\title{
К АКТУАЛЬНЫМ ВОПРОСАМ ОБЩЕЙ ТЕНДЕНЦИИ СТАРЕНИЯ НАСЕЛЕНИЯ И СОКРАЩЕНИЯ ТРУДОСПОСОБНОГО НАСЕЛЕНИЯ "
}

\author{
(C) 2020 Сиднева Вера Павловна \\ кандидат экономических наук, доцент департамента аудита и корпоративной отчетности \\ Финансовый университет при Правительстве РФ, Россия, Москва \\ E-mail: vsidneva@fa.ru
}

\section{(c) 2020 Мельникова Любовь Анатольевна}

кандидат экономических наук, доцент департамента бизнес-аналитики Финансовый университет при Правительстве РФ, Россия, Москва

E-mail: lamelnikova@fa.ru

В статье исследуются вопросы медико-демографической ситуации в России в контексте проблем постарения населения и снижения трудоспособного населения. Проблема постарения населения в настоящее время достаточно актуальна для любой страны мирового пространства. Острота проблемы обуславливается тем, что главным достоянием любой мировой страны является население этой страны. Сегодня практически все страны мира столкнулись с проблемой демографического дисбаланса вследствие демографического старения населения. Демографическое старение - это увеличение численности лиц пожилого возраста на фоне снижения числа лиц трудоспособного возраста планеты.

Наибольших темпов роста данный процесс достиг в странах Европы, США, Канаде, Австралии и Российской Федерации. Ряд стран Африки и Азии лишены данной проблемы. Проблемы демографического старения негативным образом влияют на экономику (повышают расходы на социальное, медицинское обслуживание, увеличивают дефицит трудовых ресурсов, вносят коррективы в пенсионную систему). Все эти проблемы делают актуальным изучение особенностей процессов демографического старения на любом этапе развития общества.

Изучение общей тенденции по ухудшению медико-демографической ситуации в Российской Федерации с точки зрения старения населения на ближайшие годы, необходимо рассматривать по ряду показателей и в первую очередь: рождаемости, смертности, средней продолжительности жизни и, как следствие, разным соотношением трудоспособного населения к лицам пожилого возраста. Для проведения сбалансированного исследования необходима разработка сопоставимых критериев оценки и определяющих, какое население страны следуют считать лицами старше трудоспособного возраста.

Долговременная организация медицинской помощи пожилым людям требует комплексного подхода. Она может осуществляться путем организации сестринского ухода в стационарных условиях (на койках сестринского ухода, которых сегодня крайне недостаточно) или в специализированных домах и пансионатах. Эта помощь зачастую является платной. Индивидуальный уход на дому, оказываемый близкими и родственниками больного, также требует значительных ресурсов и материальных, и психологических.

Ключевые слова: комплексный подход, медицинская помощь, население, пожилые люди, разработка критериев, ресурсы, старение, сокращение.

Постарение населения нашей страны обуславливает тенденции демографического процесса и необходимость разработки эффективной социальной политики. В поле зрения мероприятий социальной политики, учитывающей объективные демографические процессы должны входить направления изменения трудового законодательства, пенсионная реформа, вопросы миграционной политики и только комплексное и системное изучение всех направлений даст положительный результат.

«Важность проблематики постарения насе-

\footnotetext{
* Исследование выполнено в рамках научного проекта ГПХ ВТК-ГЗ-ПИ-22-20 «Прогностическая оценка объемов медицинской помощи пожилым людям»
} 
ления в Российской Федерации определяется достаточно длительным временным периодом и тесно связана с историей страны» [3].

«Старение населения - это увеличение доли пожилых людей в возрастной структуре страны или региона. Можно выделить два типа старения населения» (см. рисунок 1) [1].

Первый тип старения обуславливает доминирующий уровень удельного веса пожилых людей в общей численности населения страны, чему способствует рост продолжительности жизни населения, снижение смертности. Данный тип характерен, например, для Японии, Южной Кореи и других стран.

Старение населения «снизу» - процесс увеличения доли пожилых людей за счет увеличения только численности пожилых людей. Данный тип старения связан со снижением рождаемости и характерен для Российской Федерации [1].

Демографическое старение является естественным процессом. Данный процесс характерен для всех стран и связан со снижением рождаемости (старение снизу), что влечет за собой повышение среднего возраста населения (старение сверху). Демографическое старение присуще странам Европы, США, Канаде, некоторым странам Латинской Америки, Азии, Австралии, Новой Зеландии, Японии, не обошло оно и Российскую Федерацию. При этом в большей части стран старение идет посредствам увеличения продолжительности жизни (сверху).

Бесспорным аспектом является то, что старение населения - это естественный процесс, ему подвержены все страны мира, однако более всего он выражен в развитых странах, его определяют следующие факторы:

- рождаемость (с увеличением рождаемости происходит омоложение населения страны, с ее уменьшением - его старение);

- смертность (высокая смертность среди детей и лиц среднего возраста усиливает процессы старение населения страны, рост смертности среди лиц пожилого возраста тормозит данный процесс);

- внешняя миграция, то есть приток мигрантов в страну из других стран, который чаще состоит из лиц молодого и среднего возраста, приводит к омоложению населения страны и тормозит процессы старения, отток мигрантов в другие страны усиливает процессы старения страны;

- внутренняя миграция не оказывает значимого влияния на процессы старения популяции в стране в целом, но может существенным образом повлиять на старение населения в конкретном населенном пункте, субъекте страны, регионе;

- военные конфликты, которые ведут к безвозвратной потере населения страны чаще всего молодого и среднего возраста [5].

Исходя из возрастной периодизации ВО3, можно выделить пять возрастных этапов в жизни человека (см. рисунок 2). Индивидуальность каждого возрастного этапа сопровождается рядом особенностей (определенные плюсы и минусы того или иного возраста).

Как свидетельствуют аналитические данные

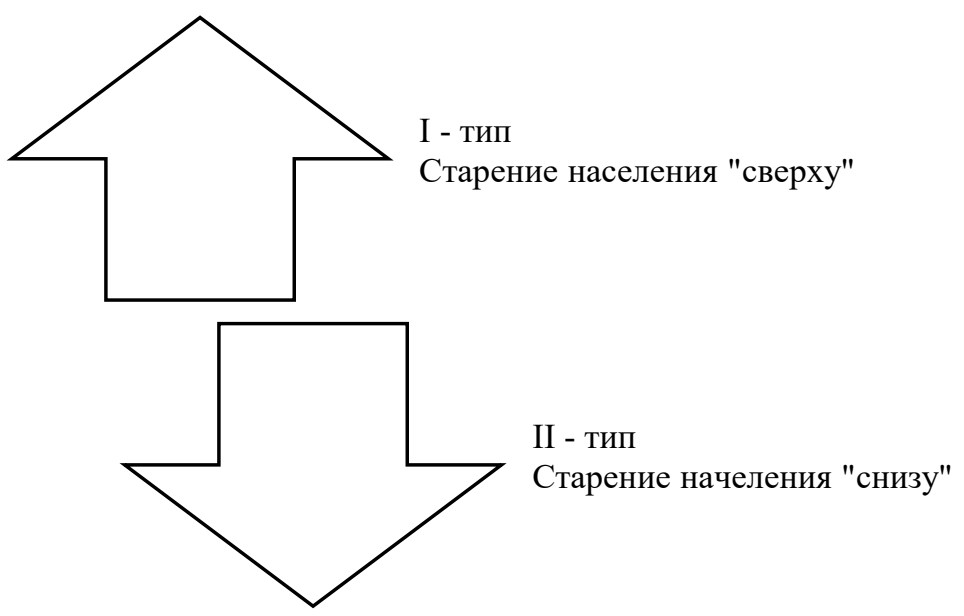

Рисунок 1. Старение населения: возможные виды Источник: составлено авторами на основе источника [1] 


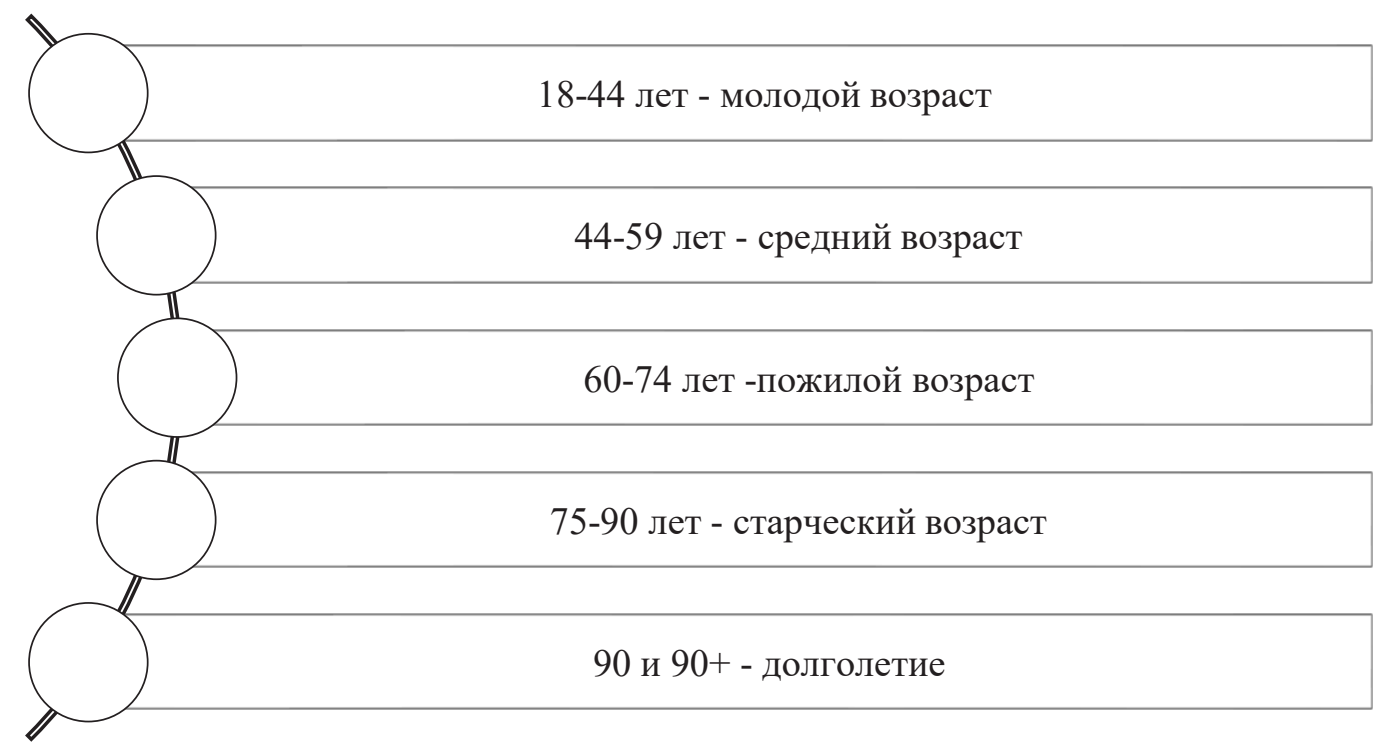

Рисунок 2. Пять возрастных этапов в жизни человека (составлено авторами на основе источника [6])

Таблица 1. Средний вариант прогноза численности (составлено авторами по данным Росстата)

\begin{tabular}{|c|c|c|c|c|c|c|}
\hline \multirow{2}{*}{ Год } & \multicolumn{2}{|c|}{$\begin{array}{c}\text { Возраст ниже } \\
\text { трудоспособного }\end{array}$} & \multicolumn{2}{|c|}{ Трудоспособный возраст } & \multicolumn{2}{|c|}{$\begin{array}{l}\text { Возраст старше } \\
\text { трудоспособного }\end{array}$} \\
\hline & тыс. человек & $\begin{array}{c}\text { \% от общего } \\
\text { значения }\end{array}$ & тыс. человек & $\begin{array}{c}\text { \% от общего } \\
\text { значения }\end{array}$ & тыс. человек & $\begin{array}{c}\text { \% от общего } \\
\text { значения }\end{array}$ \\
\hline \multicolumn{7}{|c|}{ Средний прогнозный вариант } \\
\hline 2020 & 27544,5 & 18,8 & 80720,4 & 55,0 & 38531,6 & 26,2 \\
\hline 2021 & 27585,8 & 18,8 & 80048,0 & 54,5 & 39124,0 & 26,7 \\
\hline 2022 & 27578,5 & 18,8 & 79530,8 & 54,2 & 39566,0 & 27,0 \\
\hline 2023 & 27550,9 & 18,8 & 79118,0 & 54,0 & 39910,7 & 27,2 \\
\hline 2024 & 27379,6 & 18,7 & 78872,5 & 53,8 & 40221,8 & 27,5 \\
\hline 2025 & 27104,0 & 18,5 & 78788,1 & 53,8 & 40468,6 & 27,7 \\
\hline 2026 & 26795,8 & 18,3 & 78649,6 & 53,8 & 40782,1 & 27,9 \\
\hline 2027 & 26480,1 & 18,1 & 78584,4 & 53,8 & 41004,6 & 28,1 \\
\hline 2028 & 26024,5 & 17,8 & 78637,8 & 53,9 & 41230,7 & 28,3 \\
\hline 2029 & 25450,8 & 17,5 & 78796,9 & 54,1 & 41451,5 & 28,4 \\
\hline 2030 & 24876,1 & 17,1 & 78923,6 & 54,2 & 41693,2 & 28,7 \\
\hline 2031 & 24282,4 & 16,7 & 78952,3 & 54,4 & 42040,6 & 28,9 \\
\hline 2032 & 23693,1 & 16,3 & 79041,8 & 54,5 & 42303,2 & 29,2 \\
\hline 2033 & 23160,8 & 16,0 & 79079,5 & 54,6 & 42546,1 & 29,4 \\
\hline 2034 & 22837,0 & 15,8 & 78912,5 & 54,6 & 42780,0 & 29,6 \\
\hline 2035 & 22601,0 & 15,7 & 78667,2 & 54,5 & 43002,2 & 29,8 \\
\hline 2036 & 22414,7 & 15,6 & 78289,4 & 54,3 & 43306,7 & 30,1 \\
\hline
\end{tabular}




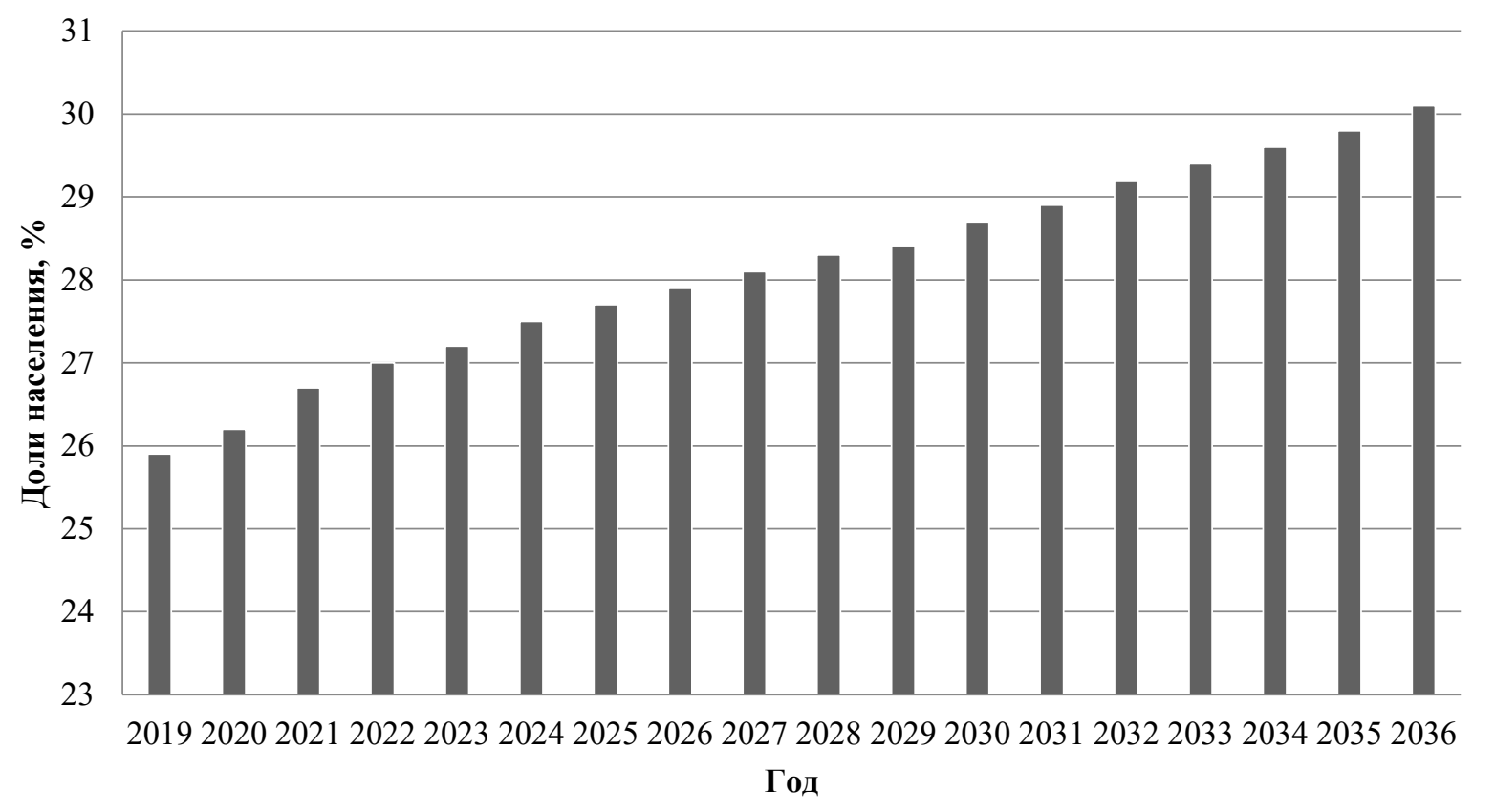

Рисунок 3. Прогноз доли населения старше трудоспособного возраста в Российской Федерации (составлено авторами по данным Росстата)

BO3, в настоящее время увеличиваются объемы медицинской и социальной помощи. Увеличение медицинской помощи в основном населению пожилого возраста и населению, имеющему хронические заболевания или инвалидность «Данные категории граждан должны быть предметом серьезной обеспокоенности во всех странах, в том числе Российской Федерации» [2].

Данные Росстата на перспективу до 2036 года свидетельствуют о том, что прогнозируется рост численности населения пожилого возраста в среднем на 14\% (таблица 1, рисунок 3).

Российская Федерация стремится выйти на уровень развитых стран по показателям социального благосостояния. Данное стремление характеризуется разработкой требований направленных на формирование эффективной системы социального обеспечения и здравоохранения населения России. Растет ценность здоровья в системе приоритетов общества, возникают новые медицинские и социальные технологии, связанные с изменениями в демографической структуре российского населения; существенно повышаются возможности реально влиять на показатели здоровья и жизни людей, о чем свидетельствуют значительные успехи в борьбе с наиболее опасными для жизни заболеваниями, достигнутые в развитых странах.

«Система здравоохранения пока еще не обеспечивает достаточность государственных гарантий медицинской помощи, ее доступность и высокое качество» [4], что обуславливает актуальность, и значимость проведения всесторонних научных исследований в части оценки объемов и качества медицинской помощи.

В заключении статьи необходимо отметить, что в Российской Федерации продолжается общая тенденция постарения населения. Негативная тенденция может быть сокращена через реализацию государственных программ помощи пожилым людям, а также программ по стимулированию рождаемости, что в долгосрочной перспективе даст положительный эффект и остановит процесс старения нации и как следствие положительно повлияет на уровень трудоспособного населения.

\section{Библиографический список}

1. Воронцов А. В. Демография: учебник и практикум для прикладного бакалавриата/ А. В. Воронцов, М.Б. Глотов.- М.: Издательство Юрайт, 2017.- 287 с.

2. Деменция: приоритет общественного здравоохранения. Всемирная организация здравоохранения [Электронныйресурс]-URL:-ttps://apps.who.int/iris/bitstream/handle/10665/75263/9789244564455_rus.pdf （дата обращения 11.05.2020). 
3. Козлов В. Современные тенденции старения населения в России. file://D:/Users/Primary/Downloads/ sovremennye-tendentsii-stareniya-naseleniya-v-rossii.pdf (дата обращения30.10.2020)

4. Распоряжение Правительства РФ от 17.11.2008 № 1662-р (ред. от 28.09.2018) «О Концепции долгосрочного социально-экономического развития Российской Федерации на период до 2020 года» (вместе с «Концепцией долгосрочного социально-экономического развития Российской Федерации на период до 2020 года»).

5. Харченко Л. П. Демография: учеб. пособие для студентов вузов, обучающихся по специальности «Статистика» и др. экономическим специальностям. - 3-е издание, стер.- М.: издательство «Омена-Л», 2009. - 350 с.

6. http://elibrary.ru/item.asp?id=39134545. 